algum tema. Índice remissivo e de fármacos completa a obra. Estudantes de graduação e pós-graduação, além de profissionais, da área de Saúde serão amplamente beneficiados com essa publicação.

Profa. Elizabeth Igne Ferreira

FCF/USP

\section{FÍSICA E QUÍMICA}

ROMERO, J. D. G. Figuras cumbres da la física y de la química. Lima: FREDY'S, 2002. 429 p.

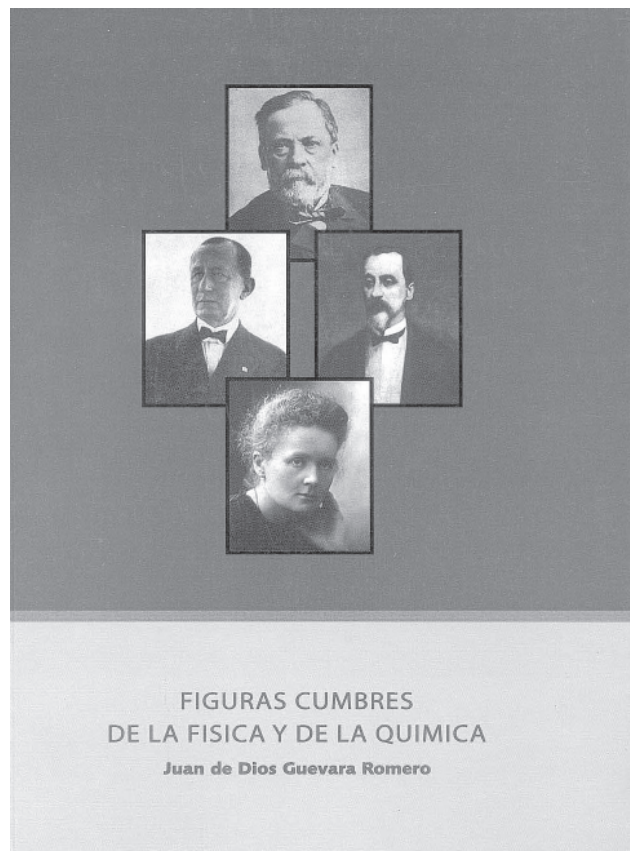

A finalidade deste livro é resumir de maneira didática e cronológica a história de 167 químicos e físicos, que, através de seus trabalhos e descobertas contribuíram significativamente com o avanço da ciência nestas duas áreas. É um resumo histórico-bibliográfico das figuras mais destacadas e conhecidas pela comunidade científica, que já conhece as leis, os princípios químicos fundamentais e os métodos de sínteses por eles determinados. No entanto, ignoram as dificuldades que estes cientistas encontraram na época em que realizaram suas descobertas, se levarmos em conta a utilização de instrumentos de medidas simples e a luta contra os preconceitos e a ignorância, nas primeiras décadas do século 20. Suas descobertas nos permitem, hoje, compreender melhor muitos dos mistérios do Universo e as bases dos princípios químicos e físicos da matéria. Grande parte destes cientistas foi agraciada com o Prêmio Nobel, a mais alta recompensa e a maior manifestação de reconhecimento no mundo da Literatura e das Ciências, instituído graças à visão e preocupação humanista de um químico: Alfredo Nobel.

Quem trabalha com pesquisa científica encontra nestas bibliografias um estímulo permanente para continuar seu aperfeiçoamento e sua missão, e superar as dificuldades que sempre se apresentarão, especialmente quando os meios econômicos são escassos. Sem dúvida, é um livro indispensável para alunos e profissionais, interessados em conhecer a vida, o trabalho e a contribuição científica que nos legaram estas 167 figuras notáveis da Química e da Física.

\section{Prof. Julio Tirapegui FCF/USP}

\section{PATOLOGIA}

IGNARRO, L.J., ed. Nitric oxide: biology and pathobiology. San Diego: Academic Press, 2000. 1003 p.

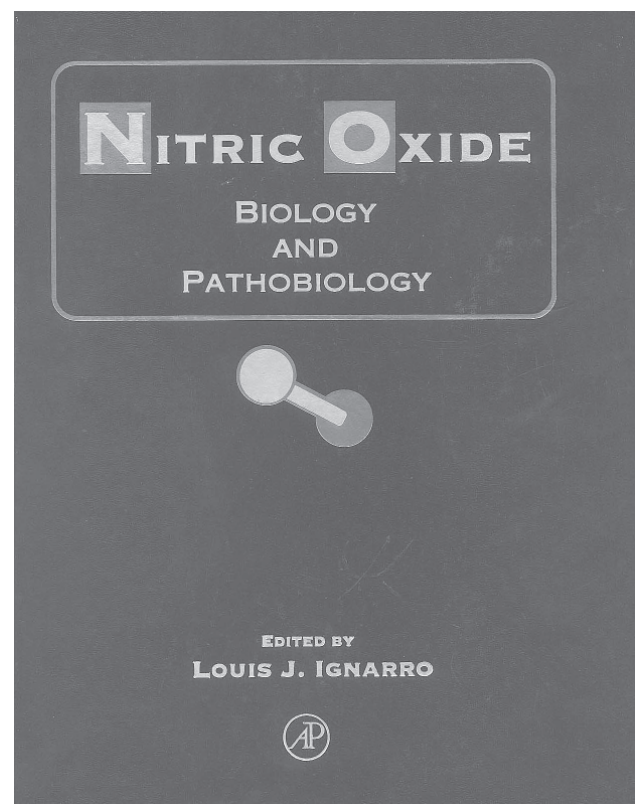

O óxido nítrico é uma das menores e mais simples moléculas biologicamente ativas na natureza, que participa de inúmeras funções celulares, atuando através de mecanismos diversos. Devido ao fato de o óxido nítrico desempenhar múltiplas funções fisiológicas, as alterações nas vias do óxido nítrico estão relacionadas com o desenvolvimento de diversas doenças, tais como, hipertensão, aterosclerose, doença arterial coronariana, falha cardíaca, acidente vascular cerebral, impotência, diabetes mellitus, asma e distúrbios do sistema nervoso central dentre outras. 
O editor deste livro, Louis J. Ignarro, foi um dos ganhadores do Prêmio Nobel em Fisiologia e Medicina, em 1998, devido às suas descobertas relacionadas às funções do óxido nítrico no sistema cardiovascular. Neste livro, o Dr. Ignarro reuniu 134 colaboradores de diversos países, que produziram um tratado que abrange todos os aspectos conhecidos sobre o óxido nítrico, desde a sua produção, química, bioquímica, transporte, aspectos fisiológicos, participação na sinalização intracelular e implicações fisiopatológicas. O livro tem 58 capítulos, que são divididos em três partes principais, a saber: Princípios Básicos (1), Princípios da Biologia (11) e Princípios da Patobiologia (HI). A parte 1 compreende um capítulo, no qual são abordados fundamentos básicos sobre a bioquímica e fisiologia do óxido nítrico. A parte 11 é subdividida em seis grandes temas, incluindo: (A) Química Biológica, (B) Óxido Nítrico Sintases, (C) Regulação da Produção de Óxido Nítrico, (D) Transporte, Interação com Membranas e Transporte de Oxigênio, (E) Óxido Nítrico e Estresse Oxidativo e (F) Mecanismos de Transdução de Sinal, com um total de 25 capítulos. Na parte M, formada por 32 capítulos, encontram-se outras quatro áreas temáticas, a saber, (A) Óxido Nítrico e o Sistema Nervoso Central, (B) Óxido Nítrico e a Função Cardiovascular, (C) Mecanismos Fisiopatológicos do Óxido Nítrico e (D) Significado Clínico do Óxido Nítrico. Todos os assuntos são abordados com profundidade, clareza e atualidade e as ilustrações, de excelente qualidade, facilitam a compreensão do texto. A bibliografia, citada ao final de cada capítulo, é bastante útil para aqueles que queiram aprofundar seus conhecimentos específicos nos diversos tópicos abordados. Esta é uma obra imprescindível para todos aqueles que atuam na pesquisa básica e aplicada, cujos temas de interesse estejam relacionados ao óxido nítrico.

Profa. Dulcineia Saes Parra Abdalla FCF/USP

\section{QUIMICA FARMACÊUTICA}

BANNWARTH, W., FELDER, E., eds. Combinatorial chemistry: a practical approach. Weinheim: Wiley-VCH, 2000. 430p.

Este compêndio discute, de forma bastante completa, assunto de grande interesse na área de planejamento e síntese de novos fármacos: a química combinatória, empregando métodos computacionais. Mediante utilização deste procedimento, a obtenção de novos modelos torna-se acelerada em relação aos métodos clássicos. Permite a

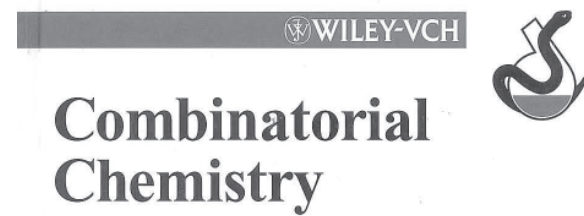

A Practical Approach

Edited by Willi Bannwarth and Eduard Felder

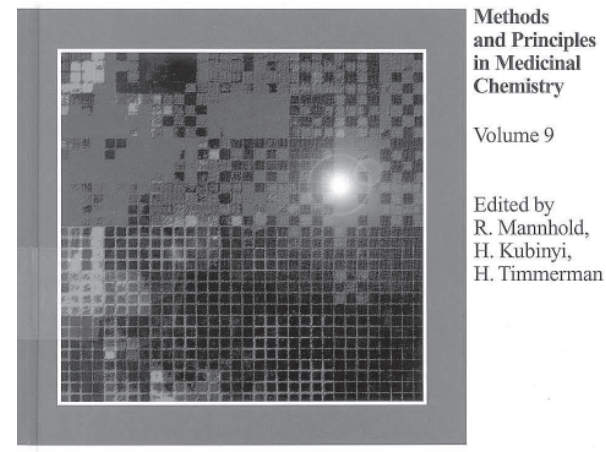

manutenção das chamadas bibliotecas de novos derivados, que, a qualquer momento, poderão ser empregados. Por outro lado, torna-se fácil a obtenção de agentes inéditos aplicando métodos sintéticos e biológicos mais rápidos $\mathrm{e}$ acessíveis. Outrossim, discute a química de fase sólida como recurso importante para a produção, em escala rápida, de múltiplas cópias. Alerta para as vantagens e desvantagens do processo. Como foi escrito por especialistas renomados, que de fato atuam na área, traz minúcias sintéticas, apresentando mecanismos de reações e equipamentos utilizados. Para se ter idéia da dimensão e importância da obra, os assuntos tratados nos capítulos são: I-Introdução geral; 2-Química Combinatória em Solvente; 3- Química em Fase Sólida (quase metade da obra); 4-Reagentes em Suportes Poliméricos; 5- Estratégias Para a Formação de Bibliotecas Combinatórias; 6-Automação e Acessórios Para Química em Fase Sólida e Síntese Orgânica Paralela (incluindo fotos e detalhes técnicos de equipamentos); 7Planejamento de Biblioteca Computacional; 8-Reações Orgânicas em Fase Sólida: Revisão Bibliográfica de 1978 a 1998. Todos os capítulos, especialmente o último, são sucedidos de farta citação bibliográfica, totalizando mais de 1300 referências. Não resta dúvida tratar-se de obra de fundamental importância a todos aqueles que atuem, não só na área farmacêutica, mas também na área das ciências de materiais. Fundamental para especialistas e alunos de pósgraduação em Farmácia.

Profa. Dra. Maria Amélia Barata da Silveira FCF/USP 